\title{
Deep Vein Thrombosis in HIV and Tuberculosis Treatment in a Case of a 19-Year-Old Guinean Student
}

\author{
Djibril Sylla ${ }^{*}$, Amadou Kake², Abdoulaye Camara ${ }^{3}$, Ibrahima Sory Barry ${ }^{3}$, Ibrahima Camara², \\ Boh Fanta Diane ${ }^{4}$, Fodé Amara Traore ${ }^{5}$, Mariame Beavogui ${ }^{3}$, Mamadou Dadhi Balde ${ }^{3}$
}

${ }^{1}$ Medico-Surgical Emergency Department of Donka National Hospital, Conakry, Guinea

${ }^{2}$ Department of Diabetes and Metabolic Diseases at Donka National Hospital, Conakry, Guinea

${ }^{3}$ Cardiac Service of Ignace Deen National Hospital, Conakry, Guinea

${ }^{4}$ Dermatology Department of Donka National Hospital, Conakry, Guinea

${ }^{5}$ Department of Infectious and Tropical Diseases at Donka National Hospital, Conakry, Guinea

Email: *docdjibril@gmail.com

How to cite this paper: Sylla, D., Kake, A., Camara, A., Barry, I.S., Camara, I., Diane, B.F., Traore, F.A., Beavogui, M. and Balde, M.D. (2019) Deep Vein Thrombosis in HIV and Tuberculosis Treatment in a Case of a 19-Year-Old Guinean Student. Open Journal of Internal Medicine, 9, 1-4.

https://doi.org/10.4236/ojim.2019.91001

Received: December 12, 2018

Accepted: February 10, 2019

Published: February 13, 2019

Copyright $\odot 2019$ by author(s) and Scientific Research Publishing Inc. This work is licensed under the Creative Commons Attribution International License (CC BY 4.0).

http://creativecommons.org/licenses/by/4.0/

\begin{abstract}
The objective of this study was to describe Thrombotic manifestations and therapeutic management during HIV infection and tuberculosis in a 19-year-old male student. The objective of this study was to describe Thrombotic manifestations and therapeutic management during HIV infection and tuberculosis in a 19-year-old student. Observation: It is Mr. S. C., aged 19, admitted for pain and swelling of the right lower limb, physical asthenia and notion of fever. Evolution 5 days, with no particular history of cardiovascular disease, anti-retroviral treatment for 1 year and anti-tuberculosis treatment for 3 months. On clinical examination heart sounds are irregular with a heart rate at $115 \mathrm{bpm}$, blood pressure at 110/70 mmhg. A febrile red painful swelling at right lower limb with positive Homans sign. $0^{\circ} \mathrm{C}$ (Temperature $37.7^{\circ} \mathrm{C}$ ), Weight at $58 \mathrm{Kg}$. The rest of the clinical examination is without particularity. Venous Doppler echo of the lower limbs: shows the presence of acute deep vein thrombosis of the right lateral vein. Mr. S. C. to benefit the following Medical Treatment: lovenox 0.6 UI subcutaneously morning and evening, Sintrom $4 \mathrm{mg} 1$ comprimed at night, Tramadol $50 \mathrm{mg}$ morning and evening; with a good clinical evolution. CONCLUSION: TB and HIV are chronic infections that result in widespread inflammation predisposing patients to a MTVE (Venous thromboembolic disease) table as well as rifampicin and anti-proteases.
\end{abstract}

\section{Keywords}

TB, HIV, Thrombosis, Young Person 


\section{Introduction}

The objective of this study was to describe thrombotic manifestations and therapeutic management during HIV infection and tuberculosis in a 19-year-old male student.

Some authors have estimated that the true prevalence of VTE may be greater than $10 \%$ but it is unknown in two thirds of cases [1]. Tuberculosis is considered a risk factor for thromboembolic venous diseases (VTE). The prevalence of this association varies between $0.6 \%$ and $10 \%$ [2]. Thromboembolic disease is increasingly reported during infection with the human immunodeficiency virus (HIV). It interests the venous territory with predilection [3].

\section{Observation}

This is Mr. S. C, aged 19, admitted for pain and swelling of the lower right limb, physical asthenia and fever concept. Evolution 5 days, no particular history of cardiovascular disease, anti-retroviral treatment for 1 year and anti-tuberculosis treatment for 3 months. On clinical examination the heart sounds are irregular with a heart rate at $115 \mathrm{bpm}$, blood pressure at 110/70 $\mathrm{mmhg}$. There is a febrile red painful swelling at the right lower limb with positive Homans sign. Temperature $37.7^{\circ} \mathrm{C}$, Weight at $58 \mathrm{Kg}$. The rest of the clinical examination is without particularity.

Mr. S. C. to benefit the following medical treatment: lovenox 0.6 UI subcutaneously morning and evening, Sintrom $4 \mathrm{mg} 1$ comprimed in the evening, Tramadol 50 mg morning and evening; with good clinical outcome RESULTS: Tuberculosis and HIV infection are chronic infections that result in widespread inflammation predisposing patients to MTVE, rifampicin, and protease inhibitors.

Electrocardiogram: normal appearance.

Facial telethorax: rounded pulmonary opacities localized in the right upper lobe.

Venous Doppler echo of the lower limbs: shows the presence of acute deep vein thrombosis of the right lateral vein.

Biology: THB at $9 \mathrm{~g} / \mathrm{l}, \mathrm{VS}$ at $\mathrm{H} 1=91 \mathrm{~mm}, \mathrm{VS}$ at $\mathrm{H} 2=102 \mathrm{~mm}, \mathrm{CRP}=60$ $\mathrm{mg} / \mathrm{l}, \mathrm{TP}=28 \%$, 1st INR: 2.41, 2nd INR: 3, Coagulation time $=26 " 4 \mathrm{~s}$, VIH positive Serologie, D-dimer à $800 \mathrm{mg} / \mathrm{ml}$, platelet count: $242 \mathrm{G} / \mathrm{l}$.

Diagnostic: In all, the diagnosis of deep vein thrombosis was retained in the field of HIV and tuberculosis.

\section{Discussion}

We report the case of a 19-year-old student with deep venous thrombosis of the lower right limb under anti-tuberculous and anti-retroviral treatment.

As early as 1856, R. Virchow described in his triad the mechanisms that can contribute to the formation of a thrombus: the alteration of coagulation, the lesion of the vascular wall and the venous stasis, these 3 mechanisms being often entangled [4]-[9]. 
Clinically, there is pain of the thrombosed limb, swelling, local heat, reduced calf wobble, dorsiflexion of the foot awakens pain (Homans sign) [10]. In our patient all these were present. Thrombosis is confirmed by veno Doppler ultrasound. It finds the incompressibility of the vein or the partial compressibility of the vein by the ultrasound probe [10]. In our case the venous ultrasonography showed the presence of acute deep vein thrombosis of the right lateral vein as illustrated in Figure 1.

Other complementary examinations are important notably phlebography which is the reference examination but remains today less and less used in clinical practice by the fact that it is invasive. The $\mathrm{D}$ dimer positive if $>500 \mathrm{ng} / \mathrm{ml}$ and they have a negative predictive value to $90 \%$ [10]. In our case the D-dimers were $800 \mathrm{ng} / \mathrm{ml}$.

Indeed, during tuberculosis several mechanisms can induce a state of blood hypercoagulability causing thromboembolic complications. Tuberculosis, in its different localizations, can induce in the blood an activation of the mononuclear cells whose interaction with Mycobacterium tuberculosis induces an increased synthesis of the interleukin 6 (IL6), the interleukin 1 and the tumor necrotif alfa factor [4] [5]. According to White, rifampicin was associated with an increased risk of DVT with a frequency of $4.74 \%$ in patients receiving rifampicin [9]; which corroborates with our clinical case.

The occurrence of venous thrombosis is classically reported during HIV infection suggesting a pro-thrombotic state of HIV infection. Our case is a perfect illustration. These thrombotic events would be multifactorial due to a state of hypercoagulability caused by HIV itself, notably through a decrease in protein C, a prolonged inflammatory state due to opportunistic infections and the iatrogenic effect of anti-proteases [6] [7] [8].

From the point of view of treatment, the patient has benefited from heparin therapy and an anti vitamin $\mathrm{K}$ allowing to have an INR in the therapeutic range

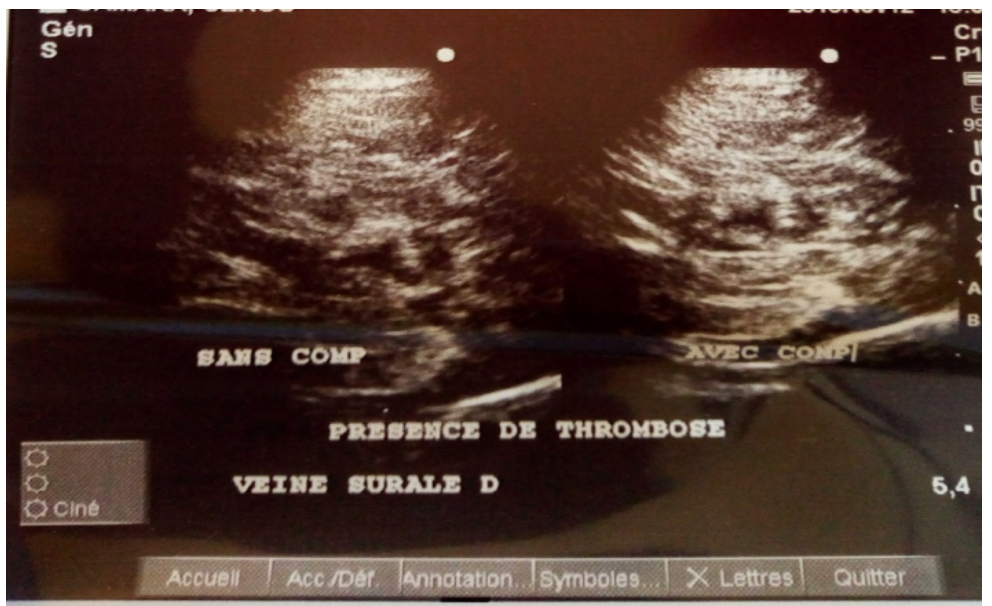

Figure 1. Left: Presence of the vein thrombosis right with compression to the probe of echography; Right: Presence of thrombosis of right lateral vein without compression at ultrasound probe. 
which is between 2 and 3 in venous thromboembolism. The evolution was favorable under treatment with the disappearance of local signs of DVT.

\section{Conclusion}

Tuberculosis and HIV infection are chronic infections that lead to widespread inflammation predisposing patients to MTVE, rifampicin, and anti proteases.

\section{Iconography}

Venous Doppler echo of the lower limbs: shows the presence of acute veinous thrombosis of the right lateral vein.

\section{Conflicts of Interest}

The authors declare no conflicts of interest regarding the publication of this paper.

\section{References}

[1] Anderson, F.A., Wheeler, H.B., Goldberg, R.J., Hosmer, D.W. and Forcier, A. (1991) Physician Practices in the Prevention of Venous Thromboembolism. Annals of Internal Medicine, 115, 591-595. https://doi.org/10.7326/0003-4819-591

[2] Malzi, I., Ardouz, E., Alami, S.M. and Marc, K. (2012) Tuberculose et maladie thromboembolique. Revue des Maladies Respiratoires, 29, A115. https://doi.org/10.1016/j.rmr.2011.10.379

[3] Tazi-Mezalek, Z., Alaoui-Bennasser, H., Maamar, M., Harmouche, H. and Adnaoui, M. (2004) Thrombose et infection à VIH: à propos de 10 cas. [Thrombosis and HIV Infection: About 10 Cases.]

[4] Turken, O., Kunter, E., Sezer, M., Solmazgul, E., Cerrahoglu, K., Bozkanat, E., et al. (2002) Hemostatic Changes in Active Pulmonary Tuberculosis. International Journal of Tuberculosis and Lung Disease, 6, 927-932.

[5] Abdelkarim, S. (2011) Spondylodiscite tuberculeuse compliquée d'une ischémie aiguë des membres inférieurs-à propos d'un cas. Pan African Medical Journal, 8, 45.

[6] Bibas, M., Biava, G. and Antinori, A. (2011) HIV Associated Venous Thromboembolism. Mediterranean Journal of Hematology and Infectious Diseases, 3, 326-329. https://doi.org/10.4084/mjhid.2011.030

[7] Crum-Cianflone, N., Weekes, J. and Bavaro, M. (2008) Thromboses among HIV Infected Patients during the HAART Era. AIDS Patient Care STDs, 22, 771-778. https://doi.org/10.1089/apc.2008.0010

[8] Lifjering, W.M., Ten Kate, M.A., Sprenger, H.G. and Van der Meer, J. (2006) Absolute Risk of Venous and Arterial Thrombosis in HIV-Infected Patients and Effects of Combination Antiretroviral Therapy. Journal of Thrombosis and Haemostasis, 4, 1928-1930. https://doi.org/10.1111/j.1538-7836.2006.02047.x

[9] White, N.W. (1989) Venous Thrombosis and Rifampicin. The Lancet, 2, 434-435. https://doi.org/10.1016/S0140-6736(89)90603-X

[10] Besse, B., Lellouche, N. and Attias, D. (2006) Epreuve nationale classante; cardiologie et maladies vasculaires; maladies veineuse thrombo embolique page 123; ed. 